\title{
Prediction of Human Disproportionate and Biliary Excreted Metabolites Using Chimeric Mice with Humanized Liver ${ }^{\text {[ }}$
}

\author{
Suguru Kato, ${ }^{1}$ Abhi Shah, Mihaela Plesescu, Yoshinari Miyata, Jayaprakasam Bolleddula, ${ }^{2}$ \\ Swapan Chowdhury, and Xiaochun Zhu
}

Drug Metabolism and Pharmacokinetics, Takeda Pharmaceutical Company Limited, Cambridge, Massachusetts (S.K., A.S., M.P., J.B., S.C., X.Z.) and Research Planning and Business Development, PhoenixBio USA Corporation, New York City, New York (Y.M.)

Received May 24, 2020; accepted July 7, 2020

\begin{abstract}
The PXB-mouse is potentially a useful in vivo model to predict human hepatic metabolism and clearance. Four model compounds, $\left[{ }^{14} \mathrm{C}\right]$ desloratadine, $\left[{ }^{3} \mathrm{H}\right]$ mianserin, cyproheptadine, and $\left[{ }^{3} \mathrm{H}\right]$ carbazeran, all reported with disproportionate human metabolites, were orally administered to PXB- or control SCID mice to elucidate the biotransformation of each of them. For $\left[{ }^{14} \mathrm{C}\right]$ desloratadine in PXB-mice, O-glucuronide of 3-hydroxydesloratadine was observed as the predominant metabolite in both the plasma and urine. Both 3-hydroxydesloratadine and its $\mathbf{O}$-glucuronide were detected as major drug-related materials in the bile, whereas only 3-hydroxydesloratadine was detected in the feces, suggesting that a fraction of 3-hydroxydesloratadine in feces was derived from deconjugation of its $\mathbf{O}$-glucuronide by gut microflora. This information can help understand the biliary clearance mechanism of a drug and may fill the gap in a human absorption, distribution, metabolism, and excretion study, in which the bile samples are typically not available. The metabolic profiles in PXB-mice were qualitatively similar to those reported in humans in a clinical study
\end{abstract}

in which 3-hydroxydesloratadine and its $\mathbf{O}$-glucuronide were major and disproportionate metabolites compared with rat, mouse, and monkey. In the control SCID mice, neither of the metabolites was detected in any matrix. Similarly, for the other three compounds, all human specific or disproportionate metabolites were detected at a high level in PXB-mice, but they were either minimally observed or not observed in the control mice. Data from these four compounds indicate that studies in PXB-mice can help predict the potential for the presence of human disproportionate metabolites (relative to preclinical species) prior to conducting clinical studies and understand the biliary clearance mechanism of a drug.

\section{SIGNIFICANCE STATEMENT}

Studies in PXB-mice have successfully predicted the human major and disproportionate metabolites compared with preclinical safety species for desloratadine, mianserin, cyproheptadine, and carbazeran. In addition, biliary excretion data from PXB-mice can help illustrate the human biliary clearance mechanism of a drug.

\section{Introduction}

One of the challenges for the drug metabolism community is to predict human major and disproportionate (relative to nonclinical safety species) circulating and biliary excreted metabolites of a drug candidate prior to conducting clinical studies. Successful prediction of human major and disproportionate circulating metabolites has many advantages, including but not limited to 1) selecting better candidates if

The work was supported by Takeda Pharmaceutical Company Limited and Chimeric Mouse with Humanized Liver Consortium.

Y.M. is an employee of PhoenixBio USA Corporation, a subsidiary of PhoenixBio Co., Ltd., Hiroshima, Japan. He participated in the study design but did not have any additional role in conducting the experiment, performing the data analysis, and preparing the manuscript. All other authors (S.K., A.S., M.P., J.B., S.C., and X.Z.) declare no competing interest.

${ }^{1}$ Current affiliation: Chugai Pharmaceuticals Co., Ltd., Tokyo, Japan.

${ }^{2}$ Current affiliation: Agios Pharmaceuticals, Inc., Cambridge, Massachusetts. https://doi.org/10.1124/dmd.120.000128.

S This article has supplemental material available at dmd.aspetjournals.org. metabolite-related issues (metabolites in safety testing issue, reactive metabolites, etc.) are identified early, 2) selecting appropriate preclinical safety species to cover major human circulating metabolites, 3) initiating synthesis of metabolite standards early, 4) identifying the need for metabolite measurement in clinical studies, 5) evaluating the pharmacological activity of the major circulating metabolites, and 6) evaluating the risk for metabolite-mediated drug-drug interaction (DDI). Bile samples are typically not obtainable in a human absorption, distribution, metabolism, and excretion (ADME) study. Prediction of human biliary excreted metabolites can shed light on the biliary excretion pathway and clearance mechanism of a drug.

In vitro preparations from human liver and various animal species have been used to predict human in vivo metabolites, but the prediction is unreliable because of the lack of correlation between in vitro and in vivo data (Anderson et al., 2009; Dalvie et al.; 2009) and species differences (Chiu and Huskey, 1998; Martignoni et al., 2006; Dalgaard, 2015). Therefore, better prediction models are constantly explored within the drug metabolism community. To mitigate the species differences, various chimeric mouse models with a humanized liver

ABBREVIATIONS: ADME, absorption, distribution, metabolism, and excretion; AO, aldehyde oxidase; BDC, bile-duct cannulated; DDI, drug-drug interaction; DL, desloratadine; Fah, fumarylacetoacetate hydrolase; FRG, Fah ${ }^{-1-} /$ Rag $^{-1-/ 12 r g-/-}$; Gl, gastrointestinal; HRMS, high-resolution mass spectrometry; IL2rg, interleukin-2 receptor gamma chain gene; LC, liquid chromatography; LC-MS, liquid chromatography-mass spectrometry; MS, mass spectrometric; NCE, new chemical entity; PXB, PhoenixBio; Rag2, recombination activating gene 2; SCID, severe combined immunodeficient; TK, thymidine kinase transgene; UGT, uridine diphosphate glucuronosyltransferase; uPA, urokinase-type plasminogen activator. 
have been developed, including urokinase-type plasminogen activator (uPA)/severe combined immunodeficient (SCID), fumarylacetoacetate hydrolase $(\mathrm{Fah})^{-/-} /$recombination-activating gene 2 $(\mathrm{Rag} 2)^{-/-}$/interleukin-2 receptor gamma chain gene (Il2rg)-/- (FRG), and thymidine kinase transgene (TK)-NOG mice (Bissig et al., 2018; Naritomi et al., 2018). Those chimeric mice have been widely used in various drug metabolism and pharmacokinetics studies (Naritomi et al., 2018) in the last decade, including prediction of human metabolites (Inoue et al., 2009; Kamimura et al., 2010; De Serres et al., 2011; Sanoh et al., 2012a; Nishimura et al., 2013; Nakada, 2017; Uehara et al., 2020), assessment of drug-drug interaction (Hasegawa et al., 2012; Nishimura et al., 2013), and prediction of human pharmacokinetics (Sanoh et al., 2012b; Miyamoto et al., 2017, 2019), etc.

PhoenixBio (PXB)-mice were originally generated using uPA/SCID mice transplanted with human hepatocytes (Tateno et al., 2004). The liver of these chimeric mice could be repopulated with more than $70 \%$ of human hepatocytes, which can potentially mimic the human hepatic metabolism. However, this model had four disadvantages: decreased human hepatocyte replacement index, potential kidney disorders, small body size, and nonhemizygote host (Tateno et al., 2015; Tateno and Kojima, 2020). To overcome those disadvantages, the model was improved by grafting cDNA-uPA/SCID mice with human hepatocytes (Tateno et al., 2015; Tateno and Kojima, 2020). The prediction of human metabolites has rarely been assessed using this improved cDNA-uPA/SCID PXB-mouse model. Although metabolism studies in mice with humanized livers have been conducted previously (Inoue et al., 2009; Kamimura et al., 2010; De Serres et al., 2011; Sanoh et al., 2012a; Nishimura et al., 2013; Nakada, 2017; Uehara et al., 2020), a comprehensive investigation with a radiolabeled drug to characterize absorption, metabolism, and excretion has not been described previously in this newer, improved mouse model. This study provides such data and biliary excretion data with metabolic profiles to understand the biotransformation and the clearance mechanism of drugs.

The primary objectives of our study were to assess whether the cDNA-uPA/SCID PXB-mice 1) can predict major and human disproportionate circulating metabolites and 2) can provide information on the clearance mechanism of drug through biliary and urinary excretion metabolic profiles. The disproportionate metabolite in this study refers to a metabolite present only in humans or present at a much higher level in any human biomatrix than that in the preclinical safety species. A successful prediction of disproportionate human metabolites means that the PXB-mouse is a superior model over other preclinical safety species for this purpose. Drug metabolism scientists can then use PXB-mice to predict human metabolic profiles and make sure potential metaboliterelated issues are resolved promptly. In addition to disproportionate metabolites, early prediction of major circulating human metabolites, even if they are not disproportionate, can allow for early evaluation of pharmacological activity and DDI potential for these metabolites and can better inform investigators in clinical trials. Since the biliary excretion data are not generally available in a radiolabeled human ADME study, the information from the study in PXB-mice will provide this important information that is not otherwise available. This study was undertaken to comprehensively evaluate the utility of the PXB-mouse model in predicting human metabolism and is thus an early assessment of the potential for major or disproportionate human metabolites. Four model compounds, desloratadine (DL), mianserin, cyproheptadine, and carbazeran, were chosen because disproportionate circulating and/or excreted metabolites of each of them have been reported in humans compared with preclinical safety species (Hucker et al., 1974; Porter et al., 1975; Fischer et al., 1980; Kaye et al., 1984; Delbressine et al.,
1992; Ramanathan et al., 2006, 2007). Three compounds were radiolabeled, including $\left[{ }^{14} \mathrm{C}\right] \mathrm{DL},\left[{ }^{3} \mathrm{H}\right]$ mianserin, and $\left[{ }^{3} \mathrm{H}\right]$ carbazeran, although cyproheptadine was not radiolabeled. The disproportionate metabolites from those four compounds were generated via cytochrome P450-, uridine diphosphate glucuronosyltransferase (UGT)-, and aldehyde oxidase (AO)-mediated metabolism (Fig. 1). Therefore, this study provides information on the utility of this model for a variety of metabolic mechanisms/pathways. Each compound was dosed to intact or bile-duct cannulated (BDC) PXB-mice or control SCID mice. Metabolite profiling and identification was conducted in plasma, urine, bile, and feces from both types of mice. The results from PXB-mice were compared with those from SCID mice and those reported in clinical and preclinical studies.

\section{Materials and Methods}

\section{Test Articles and Reagents}

$\left[{ }^{14} \mathrm{C}\right] \mathrm{DL}$ (specific activity $16.7 \mathrm{mCi} / \mathrm{mmol} ; 99.3 \%$ radiochemical purity) was synthesized as previously described (Bishop et al., 1998) at Takeda Pharmaceuticals (Cambridge, MA). [ $\left.{ }^{3} \mathrm{H}\right]$ Mianserin $(7.6 \mathrm{Ci} / \mathrm{mmol}$; radiochemical purity $>99 \%)$ and $\left[{ }^{3} \mathrm{H}\right]$ carbazeran $(6.8 \mathrm{Ci} / \mathrm{mmol}$; radiochemical purity $>99 \%)$ were synthesized by ViTrax Co. (Placentia, CA). DL was purchased from VWR International, LLC (Radnor, PA). Mianserin, cyproheptadine, and carbazeran were purchased from Sigma-Aldrich (St. Louis, MO). Ammonium formate, formic acid, and methanol (LC/MS grade) were purchased from Sigma-Aldrich. Acetonitrile (Optima LC/MS grade) and water (Optima LC/MS grade) were obtained from Thermo Fisher Scientific Inc. (Waltham, MA). Liquid scintillation cocktail Ultima Gold, Microscint-PS, Isoplate-96 microplate, and 96-well Deepwell LumaPlates were obtained from PerkinElmer (Waltham, MA).

\section{In Vivo Study Design}

In vivo study in male PXB- and SCID mice was performed at Axcelead Drug Discovery Partners, Inc. (Kanagawa, Japan) for $\left[{ }^{14} \mathrm{C}\right] \mathrm{DL}$ and was performed at Sekisui Medical (Ibaraki, Japan) for the other three compounds: $\left(\left[{ }^{3} \mathrm{H}\right]\right.$ mianserin, cyproheptadine, and $\left[{ }^{3} \mathrm{H}\right]$ carbazeran). Male PXB-mice (12-18 weeks) were provided from PhoenixBio (Hiroshima, Japan). Male SCID mice (7-14 weeks) were purchased from Charles River Laboratories Japan, Inc. (Kanagawa, Japan). The study overview is shown in Table 1. Each test compound was orally administered to the animals. Plasma, urine, bile, and fecal samples were collected at the in vivo laboratories and shipped to Takeda Pharmaceuticals for metabolite profiling and identification. The samples were stored at $-80^{\circ} \mathrm{C}$ until further analysis.

\section{Sample Pooling and Processing}

Plasma. Plasma samples collected at 4 hours after dosing were pooled at an equal volume across animals to make a single pooled plasma sample. Aliquots of pooled plasma were extracted with five volumes of methanol for $\left[{ }^{14} \mathrm{C}\right] \mathrm{DL}$ sample or three volumes of acetonitrile for $\left[{ }^{3} \mathrm{H}\right]$ mianserin, cyproheptadine, and $\left[{ }^{3} \mathrm{H}\right]$ carbazeran samples. The extraction mixture was vortexed, followed by the centrifugation. The supernatant was dried under nitrogen stream and reconstituted in appropriate solvents $\left(\left[{ }^{14} \mathrm{C}\right] \mathrm{DL}\right.$ : $50 \%$ aqueous DMSO with $0.1 \%$ formic acid; $\left[{ }^{3} \mathrm{H}\right]$ mianserin and cyproheptadine: a 4:1 mixture of $10 \mathrm{mM}$ ammonium formate in $0.1 \%$ formic acid and methanol in $0.1 \%$ formic acid; $\left[{ }^{3} \mathrm{H}\right]$ carbazeran: a $4: 1$ mixture of $0.1 \%$ acetic acid and methanol with $0.1 \%$ acetic acid). The reconstituted solution was analyzed with liquid chromatography (LC) containing a fraction collector or LC-high-resolution mass spectrometry (HRMS).

Urine. Aliquots of urine samples from 0 to 48 hours for $\left[{ }^{14} \mathrm{C}\right] \mathrm{DL},\left[{ }^{3} \mathrm{H}\right]$ mianserin, or cyproheptadine and $0-24$ hours for $\left[{ }^{3} \mathrm{H}\right]$ carbazeran were pooled proportionally to their respective weight and collected in each time interval across animals to generate a single pooled sample. The pooled urine was centrifuged. The supernatant was analyzed with LC-radioactive flow detector or LC-HRMS.

Bile. Aliquots of bile samples from 0 to 24 hours were pooled proportionally to their respective weight and collected in each time interval across animals to generate a single pooled sample. The pooled sample was centrifuged directly (for $\left[{ }^{14} \mathrm{C}\right] \mathrm{DL}$ ) or after dilution with three volumes of water (for $\left[{ }^{3} \mathrm{H}\right]$ mianserin, 
A

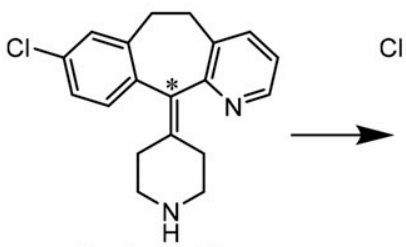
Desloratadine $*:{ }^{14} \mathrm{C}$ label

B

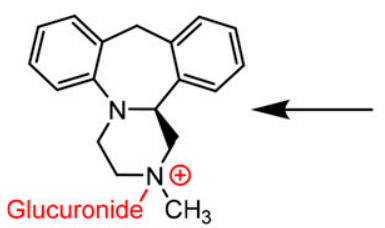

M4a, M4b<smiles>I[TlH]</smiles><smiles>CC1=C(N)C(=C2CCNCC2)c2ccc(C)cc2CC1</smiles><smiles>COc1cnc2c(c1)CCc1cc(Cl)ccc1C2=C1CCCC1(C)C(C)(C)C</smiles>

(proposed)<smiles>CN1CCN2c3ccccc3Cc3ccccc3[C@H]2C1</smiles>

Mianserin \#: ${ }^{3} \mathrm{H}$ label

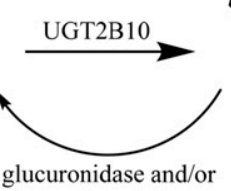

glucosidase in feces

C

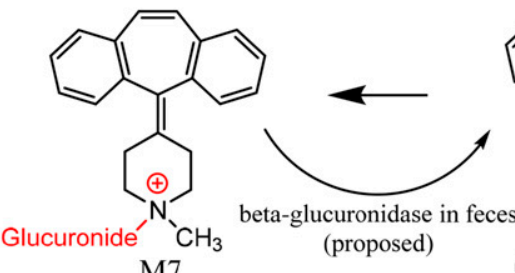
M7<smiles>CN1CCC(=C2c3ccccc3C=Cc3ccccc32)CC1</smiles>

Cyproheptadine<smiles>C[N+]1([O-])CCC(=C2c3ccccc3C=Cc3ccccc32)CC1</smiles>

M19
Fig. 1. Major metabolic pathway of desloratadine (A); metabolic pathway for formation of mianserin metabolites M4a, M4b, and M28 (B); cyproheptadine metabolites M7 and M19 (C); and carbazeran metabolite M21 (D) in humans and PXB-mice.

D<smiles>CCNC(=O)OC1CCN(c2nnc(C3CCCCC3)c3cc(OC)c(OC)cc23)CC1</smiles>

cyproheptadine, and $\left[{ }^{3} \mathrm{H}\right]$ carbazeran). The supernatant was analyzed with LCradioactive flow detector or LC-HRMS.

Fecal Homogenate. Aliquots of fecal homogenate samples from 0 to 48 hours for $\left[{ }^{14} \mathrm{C}\right] \mathrm{DL},\left[{ }^{3} \mathrm{H}\right]$ mianserin, or cyproheptadine and $0-24$ hours for $\left[{ }^{3} \mathrm{H}\right]$ carbazeran were pooled proportionally to their respective weight and collected in each time interval across animals to generate a single pooled sample. The pooled homogenate was extracted with five (for $\left[{ }^{14} \mathrm{C}\right] \mathrm{DL}$ ) or three (for $\left[{ }^{3} \mathrm{H}\right]$ mianserin, cyproheptadine, and $\left[{ }^{3} \mathrm{H}\right]$ carbazeran) volumes of acetonitrile. The extraction mixture was centrifuged, and the supernatant was separated. Additionally, 0.8 volumes of $80 \%$ aqueous acetonitrile was used to wash the pellets for $\left[{ }^{3} \mathrm{H}\right]$ mianserin and cyproheptadine, and 1.25 volumes of $80 \%$ aqueous acetonitrile was used to wash the pellets from $\left[{ }^{3} \mathrm{H}\right]$ carbazeran samples. The wash mixture was centrifuged, and the resulting supernatant was combined with the previously collected supernatant for each of the three compounds. The supernatant from each compound was then dried with nitrogen stream and reconstituted with the same solvent as the plasma samples described earlier. The reconstituted solution was analyzed with LC-radioactive flow detector or LC-HRMS.

\section{LC-Radiometric Analysis}

All samples were analyzed using an Agilent 1290 Infinity ultra-high-performance liquid chromatography (Agilent Technologies Inc., Wilmington, DE) that is composed of a binary pump, an autosampler, a temperature-controlled column compartment, a diode-array detector, and a fraction collector or a beta-RAM 5 radio flow detector (LabLogic Systems, Tampa, FL).

$\left[{ }^{14}\right.$ C $]$ DL. The method used was similar to that of a previously reported study, with some modification (Ramanathan et al., 2007). The chromatographic separation was achieved with an Inertsil C8 column $(250 \times 4.6 \mathrm{~mm}, 5 \mu \mathrm{m}$; GL Sciences, Torrance, CA) maintained at $40^{\circ} \mathrm{C}$. Mobile phases consisted of $0.1 \%$ acetic acid in $10 \mathrm{mM}$ ammonium acetate (solvent $\mathrm{A}$ ) and acetonitrile (solvent B). The following gradient program was used at a flow rate of $1 \mathrm{ml} / \mathrm{min}$ : 0-25 minutes, $10 \%-28 \%$ B; 25-40 minutes, $28 \%-90 \%$ B; $40-50$ minutes, $90 \%$ B; $50-50.1$ minutes, $90 \%-10 \%$ B ; 50.1-60 minutes, $10 \%$ B. For the plasma analysis, the LC eluate was collected at two 96-well Deepwell LumaPlates at 18.75 seconds per well, which were then dried in a vacuum centrifuge and counted for 5 minutes per well by a MicroBeta 2 plate reader (PerkinElmer). The radiometric data were then imported to Laura software (version 5.0.9.74; LabLogic Systems) to construct the radiochromatograms. For urine, bile, and fecal samples, the LC eluate was measured online using a beta-RAM 5 detector (LabLogic Systems).

$\left[{ }^{3} \mathbf{H}\right]$ Mianserin. The chromatographic separation was achieved with a Luna Phenyl-Hexyl column $(250 \times 3.0 \mathrm{~mm}, 5 \mu \mathrm{m}$; Phenomenex Inc., Torrance, CA) maintained at $40^{\circ} \mathrm{C}$. Mobile phases consisted of $0.1 \%$ formic acid in $10 \mathrm{mM}$ ammonium formate (solvent $\mathrm{A}$ ) and $0.1 \%$ formic acid in acetonitrile (solvent $\mathrm{B}$ ). The following gradient program was used at a flow rate of $0.8 \mathrm{ml} / \mathrm{min}: 0-5$ minutes, 5\% B; 5-25 minutes, 5\%-25\% B; 25-32 minutes, $25 \% \mathrm{~B} ; 32-40$ 
TABLE 1

Design of in vivo studies for male PXB- or SCID mice

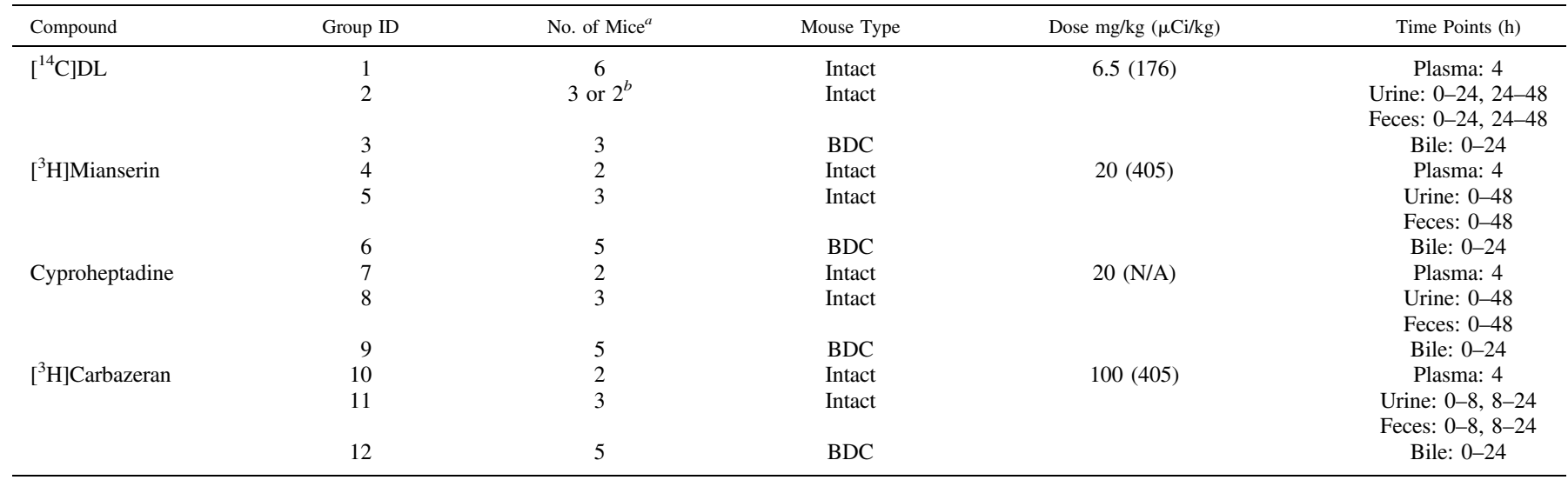

N/A, not applicable.

${ }^{a}$ Equal number of male PXB- or SCID mice were used, except where noted.

${ }^{b}$ Three PXB-mice and two SCID mice were used.

minutes, $25 \%-26.5 \% \mathrm{~B}$; 40-60 minutes, $26.5 \%-95 \% \mathrm{~B} ; 60-65$ minutes, $95 \% \mathrm{~B}$; 65-65.1 minutes, 95\%-5\% B; 65.1-70 minutes, 5\% B. The LC eluate was collected at four 96-well Isoplates at 10.94 seconds per well, which were then dried in a vacuum centrifuge and counted for 5 minutes per well by a MicroBeta2 plate reader (PerkinElmer) after mixing with scintillation cocktail. The radiometric data were then generated the same way as $\left[{ }^{14} \mathrm{C}\right] \mathrm{DL}$.

$\left[{ }^{3} \mathbf{H}\right]$ Carbazeran. The LC-radiometric analytical conditions were the same as $\left[{ }^{3} \mathrm{H}\right]$ mianserin, except for the mobile phases, the gradient program, and the radioactive detection. The mobile phases $\mathrm{A}$ and $\mathrm{B}$ were $0.1 \%$ formic acid in water and $0.1 \%$ formic acid in acetonitrile, respectively. The following gradient program was used at a flow rate of $0.6 \mathrm{ml} / \mathrm{min}: 0-2$ minutes, $2 \% \mathrm{~B} ; 2-35$ minutes, $2 \%-40 \% \mathrm{~B} ; 35-40$ minutes, $40 \%-95 \% \mathrm{~B} ; 40-45$ minutes, $95 \% \mathrm{~B}$; 45-45.1 minutes, $95 \%-2 \% \mathrm{~B} ; 45.1-50$ minutes, $2 \% \mathrm{~B}$. The LC eluate was measured online using a beta-RAM 5 detector (LabLogic Systems).

\section{LC-HRMS Analysis}

LC-HRMS was performed on an Agilent 1290 Infinity ultra-high-performance liquid chromatography (Agilent Technologies) coupled to an Orbitrap Elite Hybrid Ion Trap-Orbitrap mass spectrometer (Thermo Fisher Scientific Inc., San Jose, CA) or a TripleTOF 5600+ quadrupole time-of-flight mass spectrometer (Sciex, Concord, ON, Canada). The LC conditions were the same as those used for LC-radiometric analysis for $\left[{ }^{14} \mathrm{C}\right] \mathrm{DL},\left[{ }^{3} \mathrm{H}\right]$ mianserin, and $\left[{ }^{3} \mathrm{H}\right]$ carbazeran, respectively. For cyproheptadine, the LC conditions were the same as $\left[{ }^{3} \mathrm{H}\right]$ mianserin, except for the following gradient program at a flow rate of $0.7 \mathrm{ml} / \mathrm{min}$ : 0-5 minutes, $2 \% \mathrm{~B} ; 5-25$ minutes, 2\%-20\% B; 25-40 minutes, $20 \%-25 \% \mathrm{~B}$; $40-50$ minutes, $25 \%-95 \% \mathrm{~B}$; 50-55 minutes, 95\% B; 55-55.1 minutes, 95\%-2\% B; 55.1-60 minutes, $2 \%$ B.

$\left[{ }^{14} \mathrm{C}\right] \mathrm{DL}$ samples were analyzed on the Orbitrap Elite operated in the positive ion mode with the following conditions: capillary temperature, $400^{\circ} \mathrm{C} ; \mathrm{N}_{2}$ sheath gas flow, 75 (arbitrary units); $\mathrm{N}_{2}$ auxiliary gas flow, 20 (arbitrary units); spray voltages, $3.00 \mathrm{kV}$; S-Lens RF level, $69.1 \%$; normalized collision energy for tandem mass spectrometry acquisition, $40 \%$. The liquid chromatography-mass spectrometry (LC-MS) data were acquired and processed with Xcalibur 2.2 SP1 (Thermo Fisher Scientific, Inc).

$\left[{ }^{3} \mathrm{H}\right]$ Mianserin, cyproheptadine, and $\left[{ }^{3} \mathrm{H}\right]$ carbazeran samples were analyzed on the TripleTOF $5600+$ operated in the positive ion mode using a DuoSpray ion source with the following conditions: curtain gas, 30 (arbitrary units); ion source gas 1, 50 (arbitrary units); ion source gas 2, 50 (arbitrary units); temperature, $500^{\circ} \mathrm{C}$; ion spray voltage floating, $5500 \mathrm{~V}$; declustering potential, $60 \mathrm{~V}$; collision energy for tandem mass spectrometry acquisition, $40 \mathrm{~V}$ with a spread of $5 \mathrm{~V}$. The LC-MS data were acquired using Analyst TF 1.7 (Sciex) and processed by PeakView 2.1 (Sciex).

\section{Results}

$\left[{ }^{14}\right.$ C $]$ DL. After oral administration of $\left[{ }^{14} \mathrm{C}\right] \mathrm{DL}(6.5 \mathrm{mg} / \mathrm{kg})$, the recovery of total radioactive dose was $92.1 \%$ and $92.5 \%$ within 48 hours from intact PXB- and SCID mice, respectively (Table 2). Among them, $83.1 \%$ and $86.6 \%$ of the radioactive doses from the two mouse models, respectively, were recovered in urine and feces. The percent radioactivity in radiochromatograms and/or percent dose recovered for $\left[{ }^{14} \mathrm{C}\right] \mathrm{DL}$ and its metabolites are summarized in Table 3. The metabolic profiles between PXB- and SCID mice were quite different in all four matrices, as shown in Fig. 2. M13, 3-hydroxyldesloratadine $O$-glucuronide, was the only metabolite and the most abundant component detected in the 4-hour plasma of PXB-mice (Fig. 2A), which accounted for $69.5 \%$ of the total circulating radioactivity. In contrast, M13 was not observed in the 4-hour plasma of SCID mice (Fig. 2B), whereas DL (63.9\%) was the most abundant component, and two other metabolites, M33 (5-hydroxydesloratadine) and M31 (6-hydroxydesloratadine), were detected. M13 (49.0\% of radiochromatogram, $11.6 \%$ of dose) was the most abundant metabolite detected in urine (0-48 hours) of PXB-mice (Fig. 2C), followed by M33, DL, M31, and M40 (3-hydroxyldesloratadine). In comparison, M13 and M40 were not detected in the urine (0-48 hours) of SCID mice (Fig. 2D), whereas M33, M31, and DL were the three most abundant components in the SCID mice. DL was the predominant component in the bile (0-24 hours) of both PXB-mice (Fig. 2E) and SCID (Fig. 2F) mice. Major metabolites M40 (12.9\% of radiochromatogram, $2.7 \%$ of dose) and M13 (11.0\% of radiochromatogram, $2.3 \%$ of dose) were observed in the bile of PXB-mice, but not in that of SCID mice. In the feces (0-48 hours), DL, M33, and M31 were detected in both mice (Fig. 2, G and H). However, M40 (23.4\% of radiochromatogram, $13.9 \%$ of dose) was only detected in PXB-mice. In addition, unlike the bile, M13 was not detected in the feces of PXB-mice.

$\left[{ }^{3} \mathbf{H}\right]$ Mianserin. After oral administration of $\left[{ }^{3} \mathrm{H}\right]$ mianserin $(20 \mathrm{mg} / \mathrm{kg})$, $45.6 \%$ and $65.0 \%$ of the radioactive doses were recovered in 48 hours from PXB- and SCID mice, respectively (Supplemental Table 1). The percent radiochromatogram and/or percent dose recovered for mianserin, M4a and M4b (quaternary $N$-glucuronides), and M28 (quaternary $N$-glucoside) are summarized in Table 4 . We have identified other metabolites in PXB- and SCID mice in this study that are not discussed in this manuscript either because they were not reported as major disproportionate human metabolites relative to preclinical safety species or because they have been described previously (Delbressine et al., 1992). The metabolic profiles of plasma, bile, and feces are shown in Fig. 3. M4a and M4b accounted for $2.1 \%$ and $10.8 \%$ of total circulating radioactivity at 4 hours in $\mathrm{PXB}$-mice (Fig. 3A), but neither of them was observed in SCID mice (Fig. 3B). Consistently, both metabolites were 
TABLE 2

Excretion of radioactivity after a single oral administration of $\left[{ }^{14} \mathrm{C}\right] \mathrm{DL}(6.5 \mathrm{mg} / \mathrm{kg} ; 176 \mu \mathrm{Ci} / \mathrm{kg})$ to intact or BDC male PXB- or SCID mice

\begin{tabular}{|c|c|c|c|c|c|c|}
\hline \multirow{3}{*}{ Species } & \multirow{3}{*}{$\begin{array}{l}\text { Time } \\
\text { (h) }\end{array}$} & \multicolumn{5}{|c|}{ Cumulative Recovery of Radioactivity (\%dose) } \\
\hline & & \multicolumn{4}{|c|}{ Intact } & \multirow{2}{*}{$\begin{array}{l}\text { BDC } \\
\text { Bile }\end{array}$} \\
\hline & & Urine & Feces & $\begin{array}{l}\text { Cage } \\
\text { Wash } \\
\end{array}$ & Total & \\
\hline \multirow[t]{2}{*}{ PXB } & $0-24$ & 18.8 & 45.8 & - & 64.6 & 20.6 \\
\hline & $0-48$ & 23.7 & 59.4 & 9.0 & 92.1 & - \\
\hline \multirow[t]{2}{*}{ SCID } & $0-24$ & 38.1 & 41.9 & - & 80.0 & 7.4 \\
\hline & $0-48$ & 41.3 & 45.3 & 5.9 & 92.5 & - \\
\hline
\end{tabular}

-, data not available.

detected in urine (Table 4), bile (Fig. 3C), and feces (Fig. 3E) of PXBmice, but they were not found in any excreta of SCID mice (Table 4). Interestingly, M28, which was only observed in PXB-mice, was the predominant component and accounted for $54.5 \%$ of total radioactivity ( $5.2 \%$ of dose) in the bile. However, it was a minor component at merely $5.0 \%$ of the total radioactivity $(0.6 \%$ of dose $)$ in the feces. In contrast, mianserin was not detected in the bile, but it was observed as one of the major components in the feces (Fig. 3E). A small amount of mianserin, accounting for $1.1 \%$ of the total radioactivity $(0.3 \%$ of dose), was recovered in 0- to 48-hour feces (Fig. 3F; Table 4) of SCID mice, which suggested that this drug was well absorbed in mice.

Cyproheptadine. The LC-MS profiles of samples from PXB- and SCID mice after oral administration of cyproheptadine $(20 \mathrm{mg} / \mathrm{kg})$ are shown in Fig. 4. M7, a quaternary $\mathrm{N}$-glucuronide, was detected in the plasma of PXB-mice (Fig. 4A) but was not detected in that of SCID mice (Fig. 4B). In addition, M7 was the most abundant mass spectrometric (MS) peak in urine (data not shown) and bile (Fig. 4C) and was also detected in feces (Fig. 4D) of PXB-mice. However, this metabolite was not observed in urine, bile, or feces of SCID mice (data not shown). M19, an oxidative metabolite, was the most abundant metabolite in the plasma of PXB-mice, whereas it was a minor metabolite in that of SCID mice.

$\left[{ }^{3} \mathbf{H}\right]$ Carbazeran. The LC-MS profiles of plasma of PXB- and SCID mice after oral administration of $\left[{ }^{3} \mathrm{H}\right]$ carbazeran $(100 \mathrm{mg} / \mathrm{kg})$ are shown in Fig. 5. M21, 4-hydroxy carbazeran, was the predominant component in the plasma of PXB-mice based on the MS data (Fig. 5A), but it was a minor peak in SCID mice (Fig. 5B).

\section{Discussion}

Detection and identification of major and disproportionate human circulating metabolites in a timely manner are very important to properly assess safety liability of these metabolites without delaying the development timeline of a new chemical entity (NCE). The exposure level of human circulating metabolites accounting for more than $10 \%$ of total drug-related materials needs to be covered in preclinical safety species, or additional nonclinical study of the metabolites is warranted (https:// www.fda.gov/media/72279/download). Despite the importance of major and/or disproportionate human circulating metabolites, their identification is not available until samples from early clinical trials have been analyzed for metabolite profiling and identification. If the major or disproportionate metabolites for a given NCE were identified later in the clinical development, the follow-up studies on those metabolites may take significant time and can potentially delay the development program to registration. It is, therefore, essential that potential disproportionate human metabolites are identified in early stages and would be extremely valuable if they were identified before initiation of clinical studies. Additionally, understanding of the clearance mechanism of a drug is often obscured by lack of biliary excretion metabolic profiles in humans. The fecal metabolic profiles often do not provide information on the extent of metabolism because of the presence of unabsorbed drug, instability of certain metabolites, and deconjugation of conjugative metabolites by gut microflora in the gastrointestinal (GI) tract (Pellock and Redinbo, 2017). Furthermore, the fecal metabolism data are available only from the radiolabeled human ADME study, which is performed quite late in the clinical development of NCEs. An early assessment or understanding of a clearance mechanism can inform clinical investigators of the potential for DDI liability when combined with in vitro clearance mechanism and reaction phenotyping data.

DL is a tricyclic H1 antagonist that is used to treat allergies (Agrawal, 2001). DL was found to be extensively metabolized in five of six healthy volunteers in a clinical trial (Ramanathan et al., 2007). The major

TABLE 3

Peak distribution of DL and its metabolites in 4-h plasma, 0- to 48-h urine, 0- to 24-h bile, and 0- to 48-h feces obtained after a single oral administration of [ $\left.{ }^{14} \mathrm{C}\right] \mathrm{DL}$ $(6.5 \mathrm{mg} / \mathrm{kg} ; 176 \mu \mathrm{Ci} / \mathrm{kg})$ to intact or BDC male PXB- or SCID mice

\begin{tabular}{|c|c|c|c|c|c|c|c|c|}
\hline \multirow{4}{*}{ Component } & \multicolumn{8}{|c|}{$\%$ radiochromatogram ${ }^{a}(\% \text { dose })^{b}$} \\
\hline & \multicolumn{4}{|c|}{ PXB-Mice } & \multicolumn{4}{|c|}{ SCID Mice } \\
\hline & \multicolumn{3}{|c|}{ Intact } & \multirow{2}{*}{$\begin{array}{c}\text { BDC } \\
\text { Bile }\end{array}$} & \multicolumn{3}{|c|}{ Intact } & \multirow{2}{*}{$\begin{array}{c}\text { BDC } \\
\text { Bile }\end{array}$} \\
\hline & Plasma & Urine & Feces & & Plasma & Urine & Feces & \\
\hline DL & 30.5 & $13.8(3.3)$ & $33.7(20.0)$ & $62.2(12.8)$ & 63.9 & $16.4(6.8)$ & $35.2(15.9)$ & $100.0(7.4)$ \\
\hline M13 & 69.5 & $49.0(11.6)$ & - & $11.0(2.3)$ & - & - & - & - \\
\hline M31 & - & $12.0(2.8)$ & $11.7(6.9)$ & $4.4(0.9)$ & 6.0 & $19.4(8.0)$ & $23.3(10.6)$ & - \\
\hline M33 & - & $19.6(4.6)$ & 31.3 (18.6) & $9.6(2.0)$ & 30.1 & $62.0(25.6)$ & $41.6(18.8)$ & - \\
\hline M40 & - & $5.5(1.3)$ & $23.4(13.9)$ & $12.9(2.7)$ & - & - & - & - \\
\hline M46 & - & - & - & - & - & $2.3(0.9)$ & - & - \\
\hline
\end{tabular}

—, not detected in the radiochromatogram; ROI, region of interest.

${ }^{a_{\%}}$ radiochromatogram $=100 \times \mathrm{cpm}$ counts in each ROI/sum of $\mathrm{cpm}$ counts in all ROI.

${ }^{b} \%$ dose $=\%$ radiochromatogram $\times$ total recovery of radioactivity in each matrix. \%dose was not applicable to plasma. 

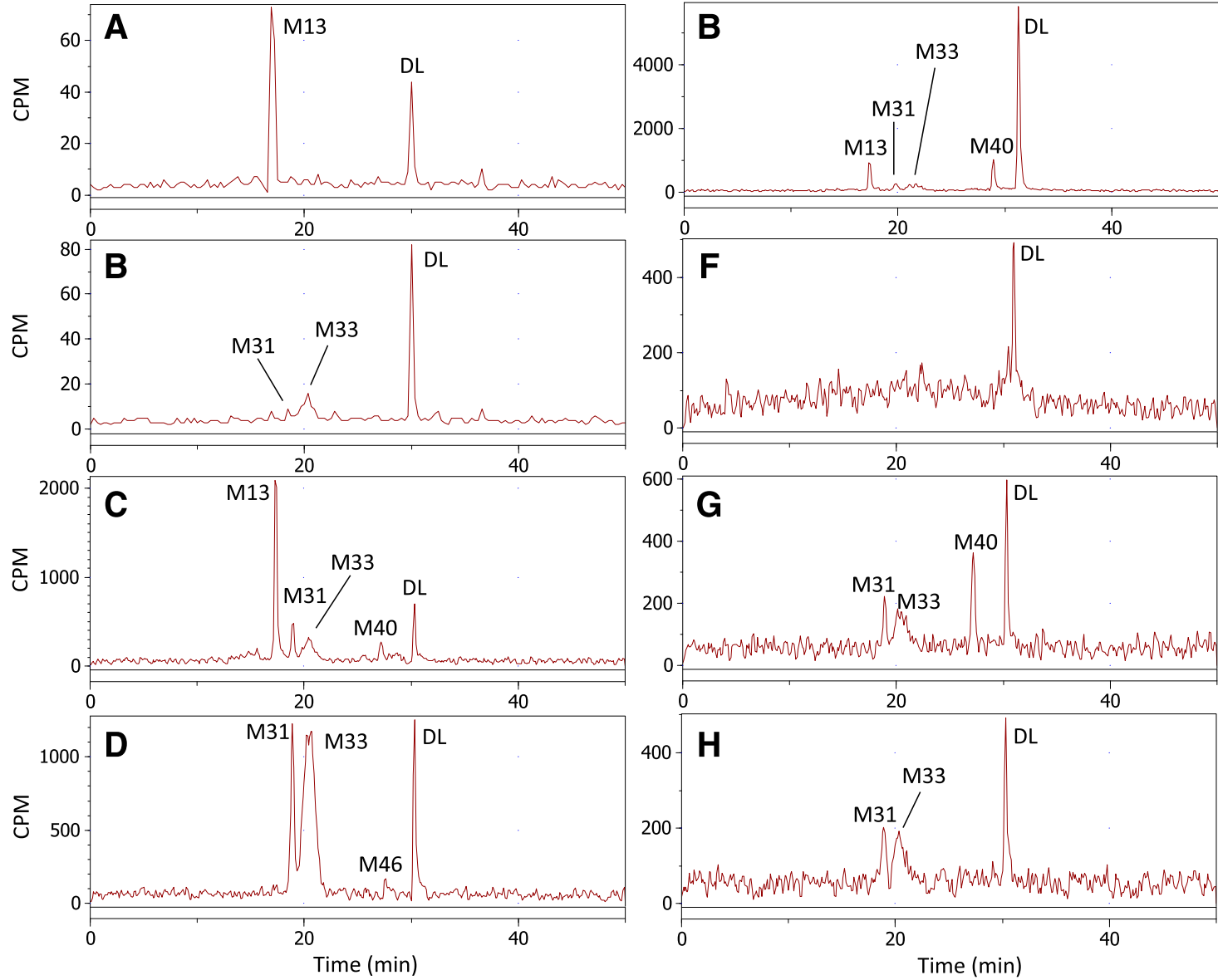

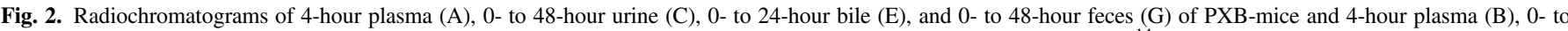
48-hour urine (D), 0- to 24 -hour bile (F), and 0- to 48-hour feces (H) of SCID mice after a single oral administration of [ $\left.{ }^{14} \mathrm{C}\right] \mathrm{DL}(6.5 \mathrm{mg} / \mathrm{kg}$; $176 \mu \mathrm{Ci} / \mathrm{kg}$ ).

biotransformation pathway was via the hydroxylation at the three position (M40) and the subsequent $O$-glucuronidation (M13) (Fig. 1A) in those five subjects. DL was poorly metabolized in the sixth subject, presumably because of the polymorphism of CYP2C8 and/or UGT2B10, which were the key enzymes that contributed to the formation of M40 (Kazmi et al., 2015). For the five extensive metabolizers, M13 accounted for $51.0 \%, 70.2 \%$, and $79.0 \%$ of the total circulating radioactivity at 3,6 , and 12 hours, respectively (Table 5). M13 was the predominant peak in urine, accounting for $22.2 \%$ of dose, and M40 was the predominant peak in feces, accounting for $28.4 \%$ of dose (Ramanathan et al., 2007). On the other hand, M13 and M40 were either not observed or detected at a trace level in plasma, urine, and feces from monkey, rat, and mouse, as shown in Supplemental Fig. 1 (Ramanathan et al., 2006). M13 was thus a disproportionate metabolite in human plasma and urine. M40, the aglycone of M13, was a disproportionate metabolite in human feces. Therefore, the significance of M13 and M40 in humans might not be realized for this drug until the clinical samples were analyzed for metabolites. However, the data from a PXB-mouse experiment could have predicted it before the drug was introduced in the clinic.

TABLE 4

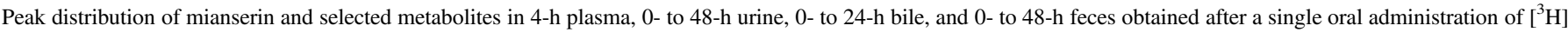
mianserin $(20 \mathrm{mg} / \mathrm{kg} ; 405 \mu \mathrm{Ci} / \mathrm{kg})$ to intact or BDC male PXB- or SCID mice

\begin{tabular}{|c|c|c|c|c|c|c|c|c|}
\hline \multirow{4}{*}{ Component } & \multicolumn{8}{|c|}{$\%$ radiochromatogram ${ }^{a}(\% \text { dose })^{b}$} \\
\hline & \multicolumn{4}{|c|}{ PXB-Mice } & \multicolumn{4}{|c|}{ SCID Mice } \\
\hline & \multicolumn{3}{|c|}{ Intact } & \multirow{2}{*}{$\begin{array}{c}\text { BDC } \\
\text { Bile }\end{array}$} & \multicolumn{3}{|c|}{ Intact } & \multirow{2}{*}{$\begin{array}{c}\text { BDC } \\
\text { Bile }\end{array}$} \\
\hline & Plasma & Urine & Feces & & Plasma & Urine & Feces & \\
\hline Mianserin & 9.4 & $4.2(1.4)$ & $8.7(1.0)$ & - & - & - & $1.1(0.3)$ & - \\
\hline M4a & 2.1 & $6.2(2.1)$ & $4.1(0.5)$ & $7.6(0.7)$ & - & - & - & - \\
\hline M4b & 10.8 & $15.9(5.4)$ & $7.0(0.8)$ & $7.7(0.7)$ & - & - & - & - \\
\hline M28 & - & $1.8(0.6)$ & $5.0(0.6)$ & $54.5(5.2)$ & - & - & - & - \\
\hline
\end{tabular}

—, not detected in the radiochromatogram; ROI, region of interest.

${ }^{a} \%$ radiochromatogram $=100 \times \mathrm{cpm}$ counts in each ROI/sum of cpm counts in all ROI

${ }^{b} \%$ dose $=\%$ radiochromatogram $\times$ total recovery of radioactivity in each matrix. \%dose was not applicable to plasma 

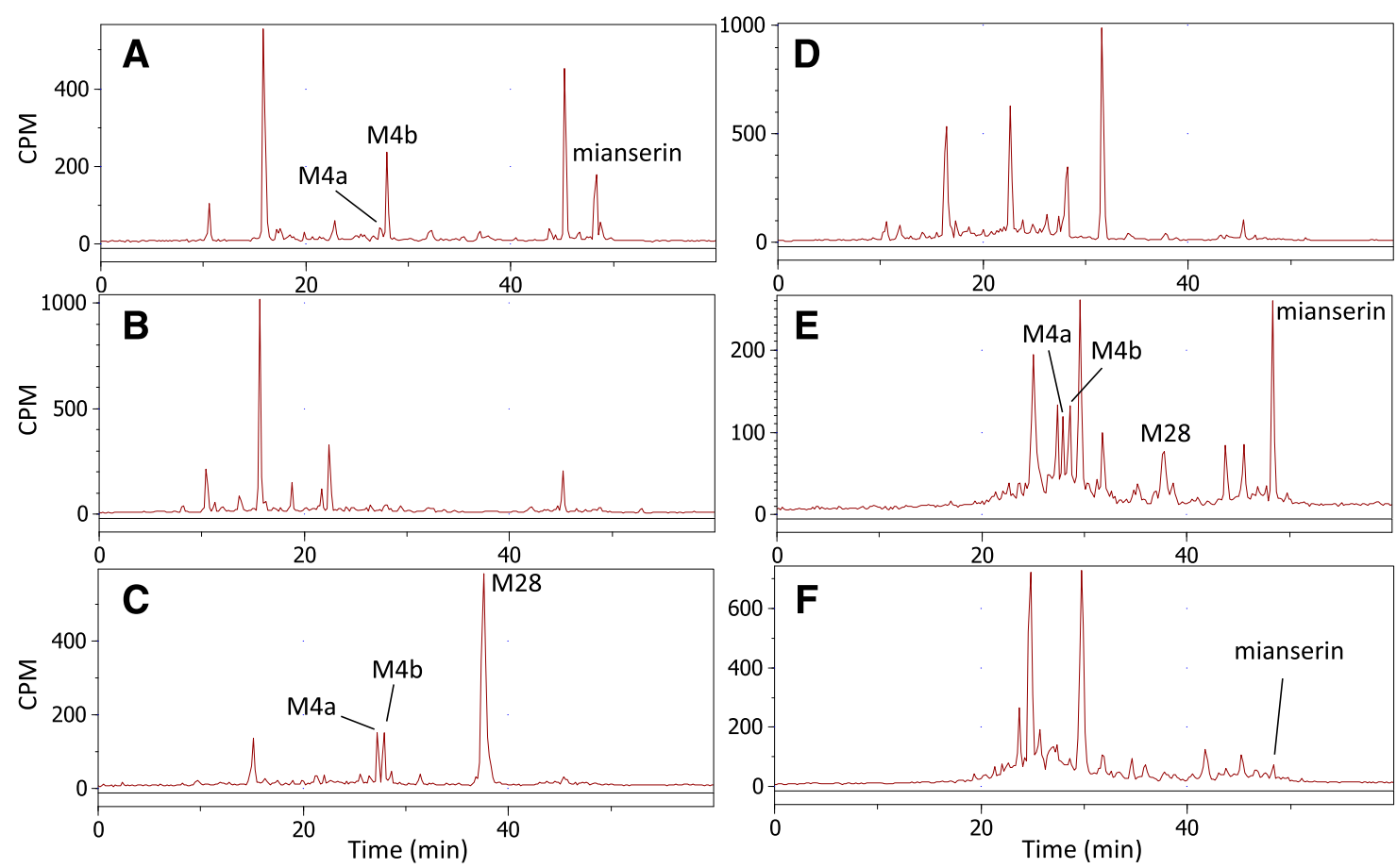

Fig. 3. Radiochromatograms of 4-hour plasma (A), 0- to 24-hour bile (C), and 0- to 48-hour feces (E) of PXB-mice and 4-hour plasma (B), 0- to 24-hour bile (D), and 0- to 48-hour feces (F) of SCID mice after a single oral administration of $\left[{ }^{3} \mathrm{H}\right] \mathrm{mianserin}(20 \mathrm{mg} / \mathrm{kg} ; 405 \mu \mathrm{Ci} / \mathrm{kg})$. All other metabolites were identified but not labeled, as they were not reported as major disproportionate human metabolites relative to preclinical safety species or have been described previously.

A comparison of the plasma metabolic profiles between PXB-mice and human subjects after administration of $\left[{ }^{14} \mathrm{C}\right] \mathrm{DL}$ is shown in Table 5 . M13, the predominant and disproportionate metabolite in human plasma at 3, 6, and 12 hours, was detected at a similar level in 4-hour plasma of PXB-mice. There was a minor difference in metabolic profile between PXB-mouse and human plasma (Fig. 2; Table 5; Ramanathan et al., 2007). DL was more abundant in PXB-mice than in human plasma. Nevertheless, this was not surprising, as the PXB-mouse liver contained a small fraction of mouse hepatocytes, whereas DL in SCID mice contributed to almost twice the circulating radioactivity in PXB-mice. Additionally, the metabolic profiles in urine and feces were similar between human and PXB-mice (Fig. 2; Supplemental Fig. 1). The results suggested that PXB-mice could have accurately predicted, at least semiquantitatively, human in vivo metabolism of DL (Table 5). The PXB-mouse was a much better model for predicting human metabolism than any other preclinical animals evaluated for this drug. Uehara et al. (2020) recently investigated the metabolism of DL by using another chimeric model, TK-NOG mice. A similar conclusion from this mouse model was drawn to that from PXB-mice in comparison with human metabolic profiles in plasma, urine, and feces. Nevertheless, nonradiolabeled DL was dosed in that study. Therefore, only metabolites with authentic standards were quantified, and the level was unknown for unmeasured metabolites. In our study, $\left[{ }^{14} \mathrm{C}\right] \mathrm{DL}$ was dosed to PXB-mice. All drug-related materials could be captured in radiochromatographic profiles. Additionally, unlike the analysis of biliary excretion of metabolites investigated in our study, a bile sample was not collected in the previous study with TK-NOG mice. In the current study, M13 and M40 were detected as major metabolites in the PXB-mouse bile (Fig. 2E), indicating that 3-hydroxylation and subsequent glucuronidation are the primary metabolism-related clearance pathways in the bile. As M13 was missing in the fecal sample (Fig. 2G) of PXB-mice, it must be hydrolyzed to M40 after bile entered the GI tract (Fig. 1A), i.e., a fraction of the M40 observed in the fecal sample was derived from deconjugation of M13. Similar to the data from PXB-mice, M13 was the predominant peak in human plasma and urine, although it was not detected in human feces (Ramanathan et al., 2007). Considering the similarity of metabolic profiles in plasma, urine, and feces between human and PXB-mice, it is reasonable to believe that biliary metabolic profiles, at least semiquantitatively, were also similar between the two species. Therefore, M13 and M40 represented the biliary excretion metabolic pathway of DL. The proposed biliary excretion of M40 based on the human fecal profile might be overestimated in the clinical trial (Ramanathan et al., 2007). This observation is particularly informative for compounds undergoing significant direct glucuronidation. On the contrary, neither M13 nor M40 was observed in SCID mice, whose metabolic profiles resembled those in CD-1 mice (Supplemental Fig. 1).

Mianserin is a tetracyclic piperazinoazepine antidepressant that is used primarily in the treatment of depression (de Jongh et al., 1981). After oral administration of $\left[{ }^{14} \mathrm{C}\right]$ mianserin to healthy volunteers, M4, a quaternary $\mathrm{N}$-glucuronide, was found in human urine, but it was not found in urine and/or feces from rat, mouse, rabbit, and guinea pig (Delbressine et al., 1992). This observation was not surprising, as species difference was observed previously in $\mathrm{N}$-glucuronidation. For example, quaternary glucuronides were preferentially formed in humans and higher primates such as chimpanzees (Chiu and Huskey, 1998). Therefore, M4 was a human disproportionate metabolite at least in urine compared with the preclinical safety species evaluated. After administration of $\left[{ }^{3} \mathrm{H}\right]$ mianserin to PXB-mice, two quaternary $\mathrm{N}$-glucuronides, M4a and M4b, were detected in plasma, urine, bile, and feces (Table 4). The two metabolites had very similar retention times in the radiochromatogram (Fig. 3), which suggests that they might be diastereomers, as mianserin had a chiral carbon, and the formation of the quaternary $\mathrm{N}$-glucuronide generated another chiral center (Fig. 1B). This fact was consistent with the previous study showing that two diastereomers were isolated for M4 (Delbressine et al., 1992), which suggests that M4 was the combined M4a and M4b. The metabolic profile of mianserin has not 


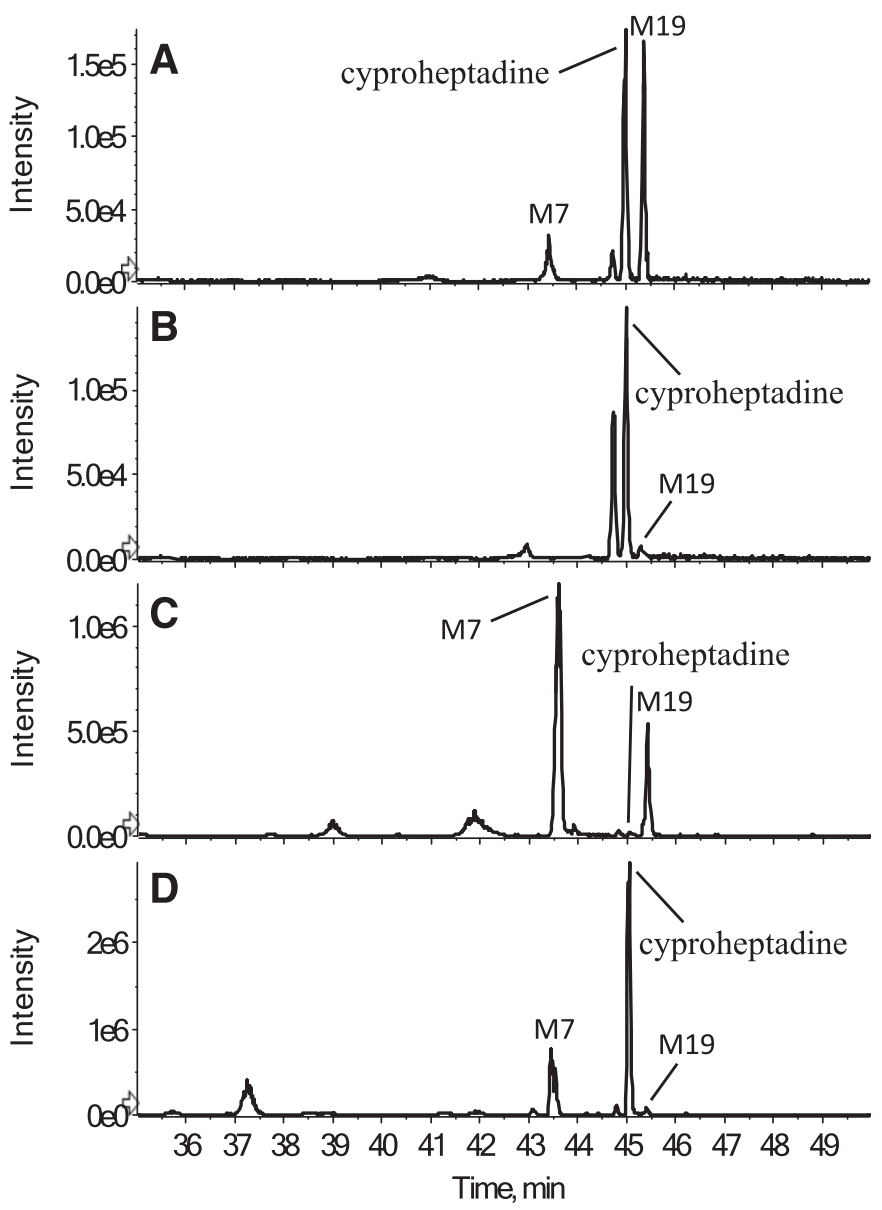

Fig. 4. Extracted ion chromatograms of the metabolite profile in 4-hour plasma of PXB- (A) and SCID (B) mice, 0- to 24-hour bile (C), and 0- to 48-hour feces (D) of PXB-mice after a single oral administration of cyproheptadine $(20 \mathrm{mg} / \mathrm{kg})$.

been reported in human plasma. Considering M4a and M4b combined was one of the most abundant metabolites in the plasma of PXB-mice, M4 was possibly one of the major circulating metabolites in humans. Interestingly, M28, a quaternary $N$-glucoside, was detected in urine, bile, and feces of PXB-mice (Fig. 1B; Table 4). This metabolite has never been reported in human ADME studies after administration of radiolabeled mianserin (de Jongh et al., 1981; Delbressine et al., 1992), but the presence of M28 in humans cannot be ruled out. The two human ADME studies reported by de Jongh et al. (1981) and Delbressine et al. (1992) were conducted at a time when the LC-MS was not available or just emerging. Because of the limitation of analytical technology, minor metabolites might be missed during the study. A recent study indicated that M28 was generated after incubation of mianserin in human liver microsomes in the presence of uridine diphosphate glucose (Lu et al., 2018). The formation of M28 was catalyzed by UGT2B10. The data in the PXB-mice from this study and in vitro data from human liver microsomes suggest that M28 might be generated in humans. In PXB-mice, M28 was the predominant component in the bile, but it was a minor metabolite in the feces. Additionally, mianserin was not observed in the bile, but it was one of the most abundant components in the feces (Fig. 3). Therefore, a fraction of M28 was probably hydrolyzed to mianserin by glucuronidase and/or glucosidase in the GI tract (Fig. 1B) (Samara et al., 1990; Flores et al., 2012). This conclusion was corroborated by the fact that the drug was well absorbed in mice, as minimal mianserin was recovered in the feces of SCID mice. In comparison with PXB-mice, none of M4a, M4b, and M28 was observed in SCID mice.

Cyproheptadine is a drug with antihistamine, anticholinergic, and antiserotonergic properties (Porter et al., 1975). After oral administration of $\left[{ }^{14} \mathrm{C}\right]$ cyproheptadine to human subjects, M7, a quaternary $\mathrm{N}$-glucuronide, was found to be the major metabolite in human urine (Fig. 1C) (Porter et al., 1975). M7 was also detected at a comparable level in urine from chimpanzees and with a significantly smaller amount in urine from various monkeys (Fischer et al., 1980). In contrast, M7 was not detected in urine from rat, dog, and cat (Hucker et al., 1974). Therefore, M7 was a disproportionate human metabolite relative to rat and dog, which are typical preclinical safety species. In our study, M7 was detected in plasma, urine (data not shown), bile, and feces of PXB-mice after administration of cyproheptadine (Fig. 4). Despite the difference in MS sensitivity for different metabolites, M7 might be the major urinary and biliary metabolite in PXB-mice, as it was the most abundant MS peak in urine and bile. M7 was the second most abundant MS peak of the metabolites in plasma, indicating that it might be one of the major circulating metabolites in humans. Cyproheptadine itself was barely detected in bile and was the most abundant MS peak in feces. Since this drug was well absorbed in animals (Hucker et al., 1974), a fraction of cyproheptadine might be produced from deconjugation of M7 by microbiota in feces (Fig. 1C). In this study, M7 was not detected in SCID mice. The formation of the quaternary $N$-glucuronide in both human and PXB-mice for both mianserin and cyproheptadine suggests that PXB-mice may be able to accurately predict the quaternary $\mathrm{N}$-glucuronidation in humans and could be a better model than the other preclinical animals in this regard. Oxidative metabolite M19 was eluted after cyproheptadine on the reversed phase LC. It was potentially the $N$-oxide of cyproheptadine (Fig. 1C), which has been detected in dog and cat urine (Hucker et al., 1974). LC-MS data indicated that M19 was a major metabolite in the plasma of PXB-mice (Fig. 4A), whereas it was a minor metabolite in the same matrix of SCID mice (Fig. 4B), suggesting that it might be a human circulating metabolite. However, the metabolic profile of cyproheptadine has never been reported for human plasma.

Carbazeran was developed as a positive inotropic agent for the treatment of congestive heart failure (Taylor et al., 1981; Kaye et al., 1984). After oral administration of $\left[{ }^{14} \mathrm{C}\right]$ carbazeran to healthy volunteers, M21 was detected as the only drug-related component in the plasma (Kaye et al., 1984). In contrast, in the dog plasma, M21 was not

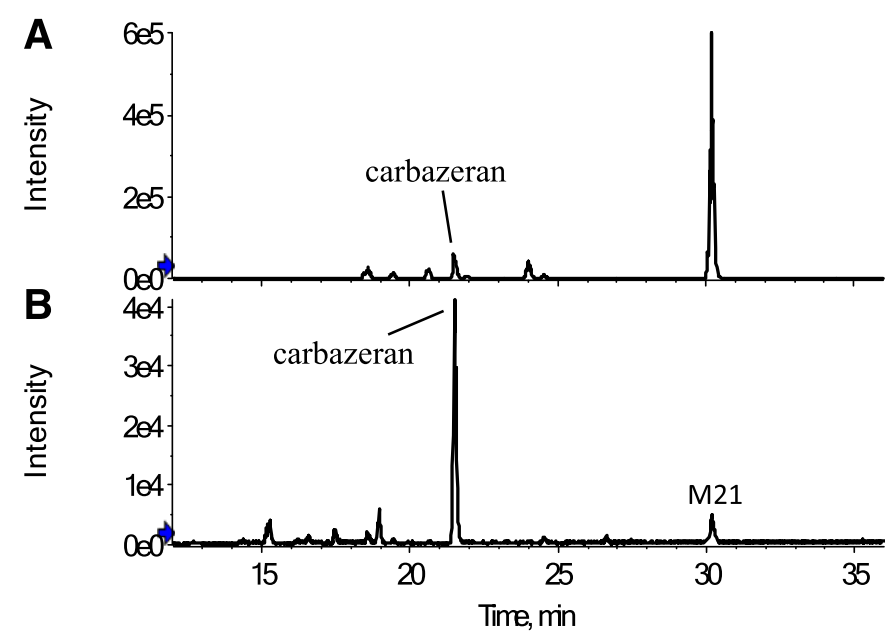

Fig. 5. Extracted ion chromatograms of the metabolite profile in 4-hour plasma of PXB- (A) and SCID (B) mice after a single oral administration of $\left[{ }^{3} \mathrm{H}\right]$ carbazeran (100 mg/kg; $405 \mu \mathrm{Ci} / \mathrm{kg}$ ). 


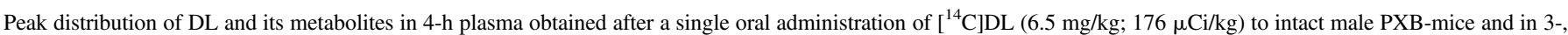
6-, and 12-h plasma obtained after a single oral administration of $\left[{ }^{14} \mathrm{C}\right] \mathrm{DL}(9.92 \mathrm{mg} ; 104 \mu \mathrm{Ci})$ to healthy male subjects

\begin{tabular}{|c|c|c|c|c|}
\hline \multirow{3}{*}{ Component } & \multicolumn{4}{|c|}{$\%$ radiochromatogram ${ }^{a}$ of Plasma Samples } \\
\hline & \multirow{2}{*}{$\begin{array}{c}\text { PXB-Mice } \\
4 \mathrm{~h}\end{array}$} & \multicolumn{3}{|c|}{ Human $^{b}$} \\
\hline & & $3 \mathrm{~h}$ & $6 \mathrm{~h}$ & $12 \mathrm{~h}$ \\
\hline DL & 30.5 & 2.4 & $<1$ & - \\
\hline M13 & 69.5 & 51.0 & 70.2 & 79.0 \\
\hline M31 & - & - & $<1$ & - \\
\hline M33 & - & - & $<1$ & - \\
\hline M40 & - & 1.3 & 4.2 & - \\
\hline Hydroxy-DL-glucuronide (M7, M9, M15a, and M17a) & - & $14.2^{c}$ & $<1$ & - \\
\hline Dihydroxy-DL-glucuronide (M5, M8, M11a) & - & $16.8^{c}$ & $25.6^{c}$ & $16.5^{c}$ \\
\hline
\end{tabular}

- not detected in the radiochromatogram; ROI, region of interest.

${ }^{a_{\%}}$ \%radiochromatogram $=100 \times \mathrm{cpm}$ counts in each region of interest $(\mathrm{ROI}) / \mathrm{sum}$ of $\mathrm{cpm}$ counts in all ROI.

${ }^{b}$ Data from the five extensive metabolizers reported in Ramanathan et al. (2007).

${ }^{c}$ More than one peak detected.

observed, whereas unchanged carbazeran accounted for $74 \%$ and $61 \%$ at 0.5 and 8 hours, respectively. Further investigation revealed that M21 was generated by AO (Kaye et al., 1985). Species variability was observed in $\mathrm{AO}$ with high activity in humans, low activity in rats and mice, and no activity in dogs (Kitamura et al., 2006). In our study, as ${ }^{3} \mathrm{H}$ was labeled at the fourth position of the phthalazine moiety, the ${ }^{3} \mathrm{H}$ label was lost during the formation of M21 (Fig. 1D). Therefore, the metabolite was not detected in the radioprofile, and the radiochromatogram is not shown for this compound. However, the LC-MS data show that, in PXB-mice, M21 was the predominant circulating metabolite, whereas carbazeran was a minor component (Fig. 5), which was consistent with the human plasma profile (Kaye et al., 1984). In comparison, M21 was a minor metabolite, whereas carbazeran was the predominant component in the plasma of SCID mice. This result suggests that $\mathrm{AO}$ activity in PXB-mice was much higher than SCID mice. Therefore, $\mathrm{PXB}$-mice may be a good animal model for prediction of AO-derived metabolites in humans.

In summary, PXB-mice successfully predicted various human disproportionate metabolites for DL, mianserin, cyproheptadine, and carbazeran compared with preclinical safety species. These metabolites include those formed by cytochrome P450, UGT, and AO. Those metabolites were not detected or observed at trace levels in the control SCID mice. The main difference between PXB- and SCID mice is that the liver of the former is replaced with more than $70 \%$ of human hepatocytes. Therefore, the accurate prediction of human metabolites by PXB-mice is primarily due to the humanized liver. In this study, we have not investigated the true quantitative nature of this prediction. However, the data presented here, although limited to only four compounds, together with other published reports (Inoue et al., 2009; De Serres et al., 2011; Sanoh et al., 2012a; Nakada, 2017) indicate that at least a semiquantitative prediction of human metabolism can be obtained in the PXB-mouse model. PXB-mice, therefore, can be a useful model to predict human major and disproportionate circulating and biliary excreted metabolites prior to clinical investigation of an NCE and thus can potentially avoid delay in clinical development of a drug should disproportionate metabolites be identified. One caveat, however, is that the PXB-mouse model may not be able to predict human circulating metabolites if the metabolites are generated from organs other than liver, such as gut or kidney.

\section{Acknowledgments}

The authors thank Dr. Linlin Dong and Jessica Wisniewski for concentration determination of mianserin, cyproheptadine, and carbazeran in plasma samples;
ISSX and Dr. Ragu Ramanathan for the permission to reprint Supplemental Fig. 1 from a poster presented at ISSX; and Chimeric Mouse with Humanized Liver (CMHL) Consortium for the support of the study.

\section{Authorship Contributions}

Participated in research design: Kato, Miyata, Bolleddula, Chowdhury, Zhu. Conducted experiments: Kato, Shah, Plesescu.

Contributed new reagents or analytic tools: Kato, Shah, Plesescu.

Performed data analysis: Kato, Shah, Zhu.

Wrote or contributed to the writing of the manuscript: Kato, Chowdhury, Zhu.

\section{References}

Agrawal DK (2001) Pharmacology and clinical efficacy of desloratadine as an anti-allergic and anti-inflammatory drug. Expert Opin Investig Drugs 10:547-560.

Anderson S, Luffer-Atlas D, and Knadler MP (2009) Predicting circulating human metabolites: how good are we? Chem Res Toxicol 22:243-256.

Bishop WR, Doll RJ, Mallams AK, Njoroge FG, Petrin JM, Piwinski JJ, Wolin RL, Taveras AG, and Remiszewski SW (1998) Tricyclic amide and urea compounds useful for inhibition of g-protein function and for treatment of proliferative diseases. U.S. patent 5,719,148. February 17, 1998.

Bissig KD, Han W, Barzi M, Kovalchuk N, Ding L, Fan X, Pankowicz FP, Zhang QY, and Ding X (2018) P450-humanized and human liver chimeric mouse models for studying xenobiotic metabolism and toxicity. Drug Metab Dispos 46:1734-1744.

Chiu SH and Huskey SW (1998) Species differences in N-glucuronidation. Drug Metab Dispos 26: 838-847.

Dalgaard L (2015) Comparison of minipig, dog, monkey and human drug metabolism and disposition. J Pharmacol Toxicol Methods 74:80-92.

Dalvie D, Obach RS, Kang P, Prakash C, Loi CM, Hurst S, Nedderman A, Goulet L, Smith E, Bu HZ, et al. (2009) Assessment of three human in vitro systems in the generation of major human excretory and circulating metabolites. Chem Res Toxicol 22:357-368.

de Jongh GD, van den Wildenberg HM, Nieuwenhuyse H, and van der Veen F (1981) The metabolism of mianserin in women, rabbits, and rats: identification of the major urinary metabolites. Drug Metab Dispos 9:48-53.

Delbressine LP, Moonen ME, Kaspersen FM, Jacobs PL, and Wagenaars GL (1992) Biotransformation of mianserin in laboratory animals and man. Xenobiotica 22:227-236.

De Serres M, Bowers G, Boyle G, Beaumont C, Castellino S, Sigafoos J, Dave M, Roberts A, Shah $\mathrm{V}$, Olson K, et al. (2011) Evaluation of a chimeric (uPA+/+)/SCID mouse model with a humanized liver for prediction of human metabolism. Xenobiotica 41:464-475.

Fischer LJ, Thies RL, Charkowski D, and Donham KJ (1980) Formation and urinary excretion of cyproheptadine glucuronide in monkeys, chimpanzees, and humans. Drug Metab Dispos 8: 422-424.

Flores R, Shi J, Gail MH, Gajer P, Ravel J, and Goedert JJ (2012) Association of fecal microbial diversity and taxonomy with selected enzymatic functions. PLoS One 7:e39745.

Hasegawa M, Tahara H, Inoue R, Kakuni M, Tateno C, and Ushiki J (2012) Investigation of drugdrug interactions caused by human pregnane $\mathrm{X}$ receptor-mediated induction of CYP3A4 and CYP2C subfamilies in chimeric mice with a humanized liver. Drug Metab Dispos 40:474-480. Hucker HB, Balletto AJ, Stauffer SC, Zacchei AG, and Arison BH (1974) Physiological disposition and urinary metabolites of cyproheptadine in the dog, rat, and cat. Drug Metab Dispos 2: 406-415.

Inoue T, Sugihara K, Ohshita H, Horie T, Kitamura S, and Ohta S (2009) Prediction of human disposition toward S-3H-warfarin using chimeric mice with humanized liver. Drug Metab Pharmacokinet 24:153-160.

Kamimura H, Nakada N, Suzuki K, Mera A, Souda K, Murakami Y, Tanaka K, Iwatsubo T, Kawamura A, and Usui T (2010) Assessment of chimeric mice with humanized liver as a tool for predicting circulating human metabolites. Drug Metab Pharmacokinet 25:223-235.

Kaye B, Offerman JL, Reid JL, Elliott HL, and Hillis WS (1984) A species difference in the presystemic metabolism of carbazeran in dog and man. Xenobiotica 14:935-945. 
Kaye B, Rance DJ, and Waring L (1985) Oxidative metabolism of carbazeran in vitro by liver cytosol of baboon and man. Xenobiotica 15:237-242.

Kazmi F, Barbara JE, Yerino P, and Parkinson A (2015) A long-standing mystery solved: the formation of 3-hydroxydesloratadine is catalyzed by CYP2C8 but prior glucuronidation of desloratadine by UDP-glucuronosyltransferase $2 \mathrm{~B} 10$ is an obligatory requirement. Drug Metab Dispos 43:523-533.

Kitamura S, Sugihara K, and Ohta S (2006) Drug-metabolizing ability of molybdenum hydroxylases. Drug Metab Pharmacokinet 21:83-98.

Lu D, Dong D, Xie Q, Li Z, and Wu B (2018) Disposition of mianserin and cyclizine in UGT2B10overexpressing human embryonic kidney 293 cells: identification of UGT2B10 as a nove $\mathrm{N}$-glucosidation enzyme and breast cancer resistance protein as an N-glucoside transporter. Drug Metab Dispos 46:970-979.

Martignoni M, Groothuis GM, and de Kanter R (2006) Species differences between mouse, rat, dog, monkey and human CYP-mediated drug metabolism, inhibition and induction. Expert Opin Drug Metab Toxicol 2:875-894.

Miyamoto M, Iwasaki S, Chisaki I, Nakagawa S, Amano N, and Hirabayashi H (2017) Comparison of predictability for human pharmacokinetics parameters among monkeys, rats, and chimeric mice with humanised liver. Xenobiotica 47:1052-1063.

Miyamoto M, Iwasaki S, Chisaki I, Nakagawa S, Amano N, Kosugi Y, and Hirabayashi H (2019) Prediction of human pharmacokinetics of long half-life compounds using chimeric mice with humanised liver. Xenobiotica 49:1379-1387.

Nakada N (2017) Evaluation of the utility of chimeric mice with humanized livers for the characterization and profiling of the metabolites of a selective inhibitor (YM543) of the sodiumglucose cotransporter 2. Pharm Res 34:874-886.

Naritomi Y, Sanoh S, and Ohta S (2018) Chimeric mice with humanized liver: application in drug metabolism and pharmacokinetics studies for drug discovery. Drug Metab Pharmacokinet 33 31-39.

Nishimura T, Hu Y, Wu M, Pham E, Suemizu H, Elazar M, Liu M, Idilman R, Yurdaydin C, Angus P, et al. (2013) Using chimeric mice with humanized livers to predict human drug metabolism and a drug-drug interaction [published correction appears in J Pharmacol Exp The (2013) 345:327]. J Pharmacol Exp Ther 344:388-396.

Pellock SJ and Redinbo MR (2017) Glucuronides in the gut: sugar-driven symbioses between microbe and host. J Biol Chem 292:8569-8576.

Porter CC, Arison BH, Gruber VF, Titus DC, and Vandenheuvel WJ (1975) Human metabolism of cyproheptadine. Drug Metab Dispos 3:189-197.
Ramanathan R, Reyderman L, Su AD, Alvarez N, Chowdhury SK, Alton KB, Wirth MA, Clemen RP, Statkevich P, and Patrick JE (2007) Disposition of desloratadine in healthy volunteers. Xenobiotica 37:770-787.

Ramanathan R, Su AD, Alvarez N, Feng W, Chowdhury SK, Stauber K, Reyderman L, Alton KB Wirth M, and Patrick JE (2006) Metabolism and excretion of desloratadine (clarinex) in mice, rats, monkeys and humans, in The 14th North American ISSX Meeting; Rio Grande, Puerto Rico, October 22-26.

Samara E, Bialer M, and Harvey DJ (1990) Identification of glucose conjugates as major urinary metabolites of cannabidiol in the dog. Xenobiotica 20:177-183.

Sanoh S, Horiguchi A, Sugihara K, Kotake Y, Tayama Y, Ohshita H, Tateno C, Horie T, Kitamura S, and Ohta S (2012b) Prediction of in vivo hepatic clearance and half-life of drug candidates in human using chimeric mice with humanized liver. Drug Metab Dispos 40:322-328.

Sanoh S, Nozaki K, Murai H, Terashita S, Teramura T, and Ohta S (2012a) Prediction of human metabolism of FK3453 by aldehyde oxidase using chimeric mice transplanted with human or rat hepatocytes. Drug Metab Dispos 40:76-82.

Tateno C, Kawase Y, Tobita Y, Hamamura S, Ohshita H, Yokomichi H, Sanada H, Kakuni M, Shiota A, Kojima Y, et al. (2015) Generation of novel chimeric mice with humanized livers by using hemizygous cDNA-uPA/SCID mice. PLOS One 10:e142145.

Tateno C and Kojima Y (2020) Characterization and applications of chimeric mice with humanized livers for preclinical drug development. Lab Anim Res 36:2-9.

Tateno C, Yoshizane Y, Saito N, Kataoka M, Utoh R, Yamasaki C, Tachibana A, Soeno Y, Asahina K, Hino H, et al. (2004) Near completely humanized liver in mice shows human-type metabolic responses to drugs. Am J Pathol 165:901-912.

Taylor CR, Baird JR, Blackburn KJ, Cambridge D, Constantine JW, Ghaly MS, Hayden ML, McIlhenny HM, Moore PF, Olukotun AY, et al. (1981) Comparative pharmacology and clinical efficacy of newer agents in treatment of heart failure. Am Heart $J$ 102:515-532.

Uehara S, Yoneda N, Higuchi Y, Yamazaki H, and Suemizu H (2020) Metabolism of desloratadine by chimeric TK-NOG mice transplanted with human hepatocytes. Xenobiotica 50:733-740.

Address correspondence to: Xiaochun Zhu, Drug Metabolism and Pharmacokinetics, Takeda Pharmaceutical Company Limited, 35 Landsdowne St, Cambridge, MA 02139. E-mail: xiaochun.zhu@takeda.com 